\title{
Mechano-hydraulic pumping solutions for reduction off energy losses in agricultural mobile machinery
}

\author{
Alexandru Hristea ${ }^{1 *}$, Bogdan Tudor ${ }^{1}$, Stefan Sefu ${ }^{1}$ and Gabriela Milian ${ }^{2}$ \\ ${ }^{1}$ INOE 2000-IHP, street Cutitul de Argint, no. 14, Sector 4, Bucharest, Romania \\ ${ }^{2}$ INMA, street Ion Ionescu de la Brad, no. 6, Sector 1, Bucharest, Romania
}

\begin{abstract}
Hydraulic digital power consists in a hydraulic plant having one or more discreet valued components actively with which we are controlling the system output flow. In this paper authors study a solution of 4 fixed pumps parallel connected. This complex pumping system can achieve 15 flows. The pumping system consists in an electrical single speed motor, 4 fixed pumps, the repartition will achieve with the help of 4 electrohydraulic distributors and an electronic micro-controller. The hydraulic plant was made in our Research Institute in the digital hydraulic laboratory for conducting tests and experiments.
\end{abstract}

\section{Introduction}

The evolution of technology was one of the biggest developments for human society, and within it a very important role it has played by the development of mechanical, electrical, hydraulic and pneumatic drives. Further will be analyzed how the hydraulic drive past from movements required in order to achieve the role of agricultural machinery to technical means of making movements with energy losses as low as possible. This shift towards energy saving was made in time, in several stages, each stage being represented by a specific technology.

In the first stage, with fixed pump systems, initial achievements were oriented toward movements' realization and only secondarily to reducing energy consumption by reducing losses [1].

In the second stage, adjustable stage pump systems, was pursued to modify the displacement of the pumps (power consumption) during operation, by means of mechanohydraulic means like controllers.

${ }^{*}$ Corresponding author: hristea.ihp $@$ fluidas.ro 
The third stage, the energy consumption approach one (from the primary source) to the requirements of each phase of the cycle of operation, is dominated by equipping adjustable pumps with devices controlled with servo equipment or load sensing [2].

In the fourth stage, the digital hydraulics, was passed from the regulation of the pump, in order to reduce losses, to the use of several units of the system to close the primary energy consumption to energy needs of the driven machinery.

Great novelty of the 90s was the transfer of digital hydraulics from theory to real world practice. This thing was manageable due to specialists such as Scheidl, Linjama, Vilenius, Bishop, Wadsley, Merrill, Kudzma, Ploeckinger, etc., who had the first notable practice results.[3]

Digital Fluid Power means hydraulic and pneumatic systems having discrete valued component(s) actively controlling system output. Very important for digital hydraulics is the "intelligent control". In Europe there is accepted that digital hydraulics has a branch that was based on parallel connections, with a center located in Tampere, and a branch based on the switching technology in Linz. It should be specified that digital hydraulics does not mean traditional hydraulics, classic or modern with analog element which we drive with digital electronics. Digital hydraulics means hydraulics or pneumatics systems which have in their structure at least one hydraulic element to ensure at the exit specifically discrete values and active control. This thing involves beside the digital hydraulic elements a proper electronic command, so a good computerization of the system.

\section{The advantages of digital hydraulics}

The advantages of digital hydraulics are extremely clear at the theoretical level, but less visible in industrial practice. The hopes related to speed, robustness, simplicity and equipment reliability is not yet materialized in industrial products used on the large scale or in some specific areas. Comparative with the standard on/off hydraulics, digital hydraulics has a response time much smaller, but it keeps the durability and work capacity in dirty mediums of the classic hydraulics drives. Specialists from Tampere estimate that there is the possibility to save a percentage of fuel between 20 and $40 \%$, machines becoming simpler and light-weight without a price rising. Digitization of all mobile machines can reduce consumption on road with a percentage between 5 and $10 \%$. Even the general architecture of the hydraulically operated vehicle can be simplified by using digital hydraulics, as in figures 1, 2, as indicated by L. Wadsley.[4]

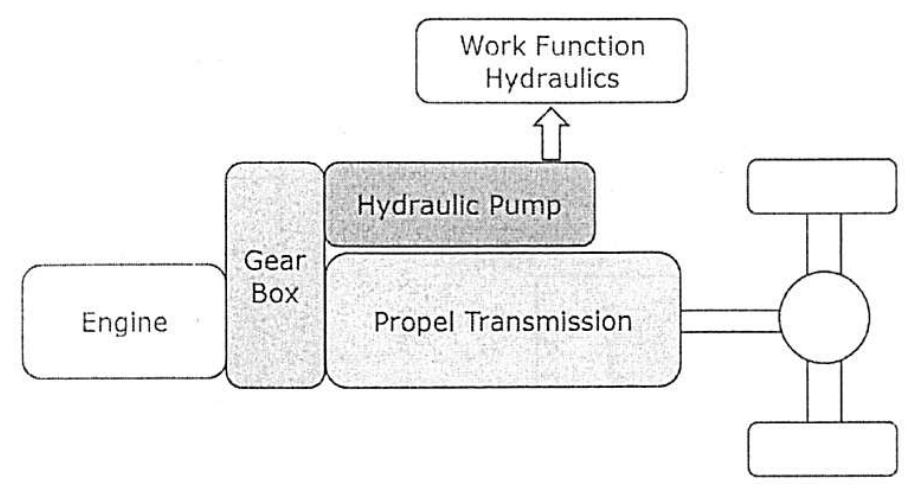

Fig. 1. Typical mobile machine layout [4] 


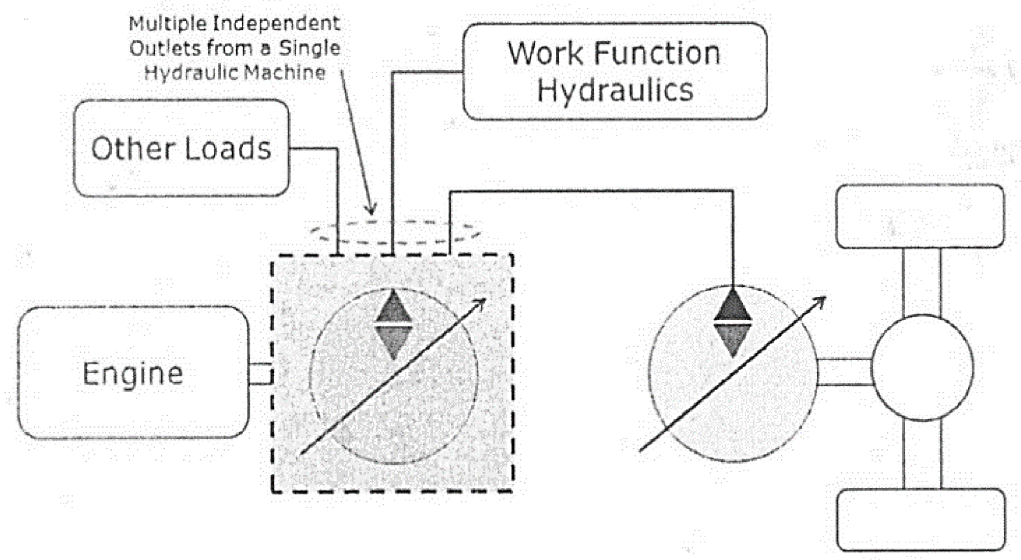

Fig. 2. Alternative mobile machine layout [4]

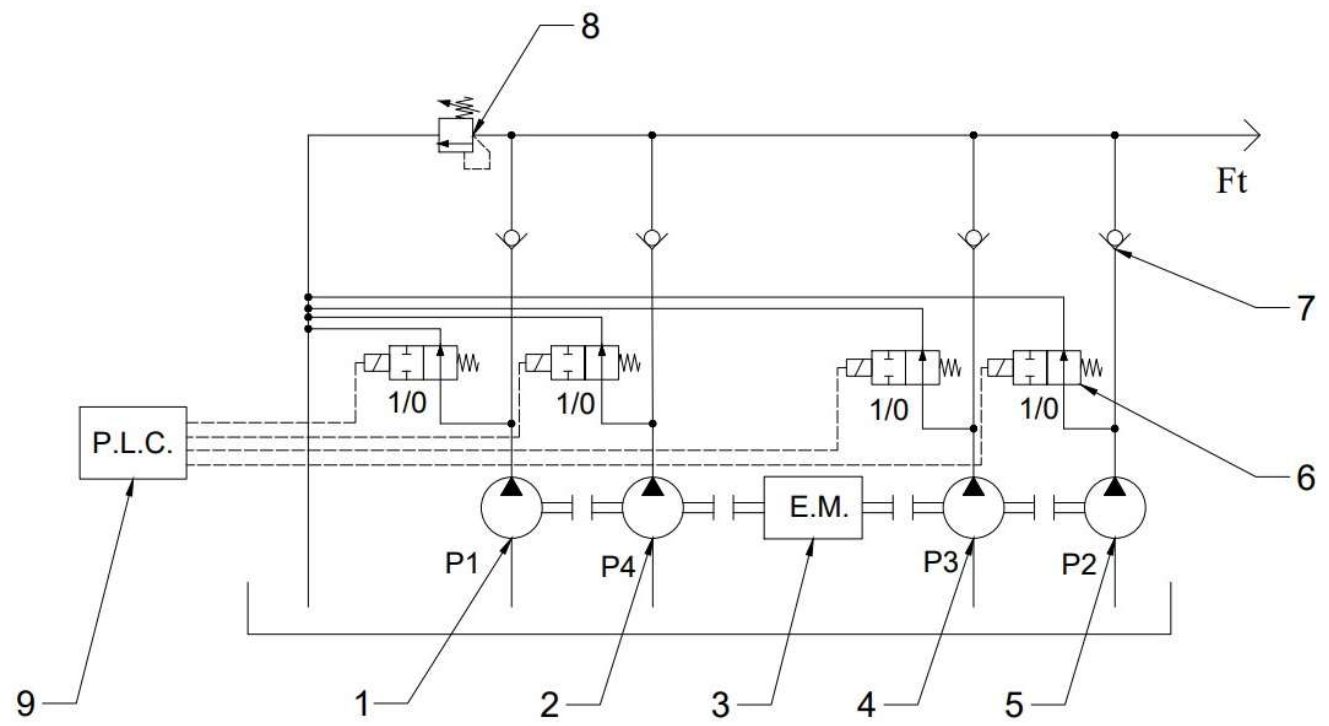

Fig. 3. Hydraulic system with 4 fixed displacement pumps consists in: $(1,2,4,5)$ fixed displacement pumps, (3) biaxial electric motor, (6) 2/2 directional valve, (7) one-way valve, (8) pressure relies valve

\section{The 4 fix displacement pumps solution with 15 selectable flows}

Hydraulic systems which used pumping units with 4 coaxial pumps (Figure 3) or 4 pumps driven by independent electric/thermic motor were actually the first steps towards digital hydraulics. Each pump has its own flow (Q1, Q2, Q3, Q4) of which we can select for the system one, two or even all for, getting the flow rates with the help of a programable logic controller (P.L.C.): 
Table.1 Depending on flow requirements, one or more pumps will be selected

\begin{tabular}{|c|c|c|c|c|}
\hline Nr.crt. & $\begin{array}{c}\text { Pump } \\
\text { combination }\end{array}$ & $\begin{array}{l}\text { Total displacement } \\
{\left[\mathrm{cm}^{3} / \mathrm{rot}\right]}\end{array}$ & $\begin{array}{c}\text { System Flow } \\
{[\mathrm{L} / \mathrm{min}]}\end{array}$ & $\begin{array}{c}\text { Power N } \\
{[\mathrm{kW}]}\end{array}$ \\
\hline 1 & $\mathrm{P} 1$ & 4 & 6 & 2 \\
\hline 2 & $\mathrm{P} 2$ & 8 & 12 & 4 \\
\hline 3 & $\mathrm{P} 1+\mathrm{P} 2$ & 12 & 18 & 6 \\
\hline 4 & P3 & 16 & 24 & 8 \\
\hline 5 & $\mathrm{P} 3+\mathrm{P} 1$ & 20 & 30 & 10 \\
\hline 6 & $\mathrm{P} 3+\mathrm{P} 2$ & 24 & 36 & 12 \\
\hline 7 & $\mathrm{P} 3+\mathrm{P} 2+\mathrm{P} 1$ & 28 & 42 & 14 \\
\hline 8 & $\mathrm{P} 4$ & 32 & 48 & 16 \\
\hline 9 & $\mathrm{P} 4+\mathrm{P} 1$ & 36 & 54 & 18 \\
\hline 10 & $\mathrm{P} 4+\mathrm{P} 2$ & 40 & 60 & 20 \\
\hline 11 & $\mathrm{P} 4+\mathrm{P} 2+\mathrm{P} 1$ & 44 & 66 & 22 \\
\hline 12 & $\mathrm{P} 4+\mathrm{P} 3$ & 48 & 72 & 24 \\
\hline 13 & $\mathrm{P} 4+\mathrm{P} 3+\mathrm{P} 1$ & 52 & 78 & 26 \\
\hline 14 & $\mathrm{P} 4+\mathrm{P} 3+\mathrm{P} 2$ & 56 & 84 & 28 \\
\hline 15 & $\begin{array}{l}\mathrm{P} 4+\mathrm{P} 3+\mathrm{P} 2+\mathrm{P} \\
1\end{array}$ & 60 & 90 & 30 \\
\hline
\end{tabular}

$\mathrm{P} 1=$ First pump with the flow displacement of $4 \mathrm{~cm}^{3} / \mathrm{rot}$

$\mathrm{P} 2=$ Second pump with the flow displacement of $8 \mathrm{~cm}^{3} / \mathrm{rot}$

$\mathrm{P} 3=$ Third pump with the flow displacement of $16 \mathrm{~cm}^{3} / \mathrm{rot}$

$\mathrm{P} 4=$ Forth pump with the flow displacement of $32 \mathrm{~cm}^{3} / \mathrm{rot}$

The flow rate from the column four was calculated at the nominal speed of $1500 \mathrm{rpm}$

Using the electric automation system there is selected one of the 15 variants of flow, which can provide one of the 15 different speeds for the hydraulic motor E.M. 


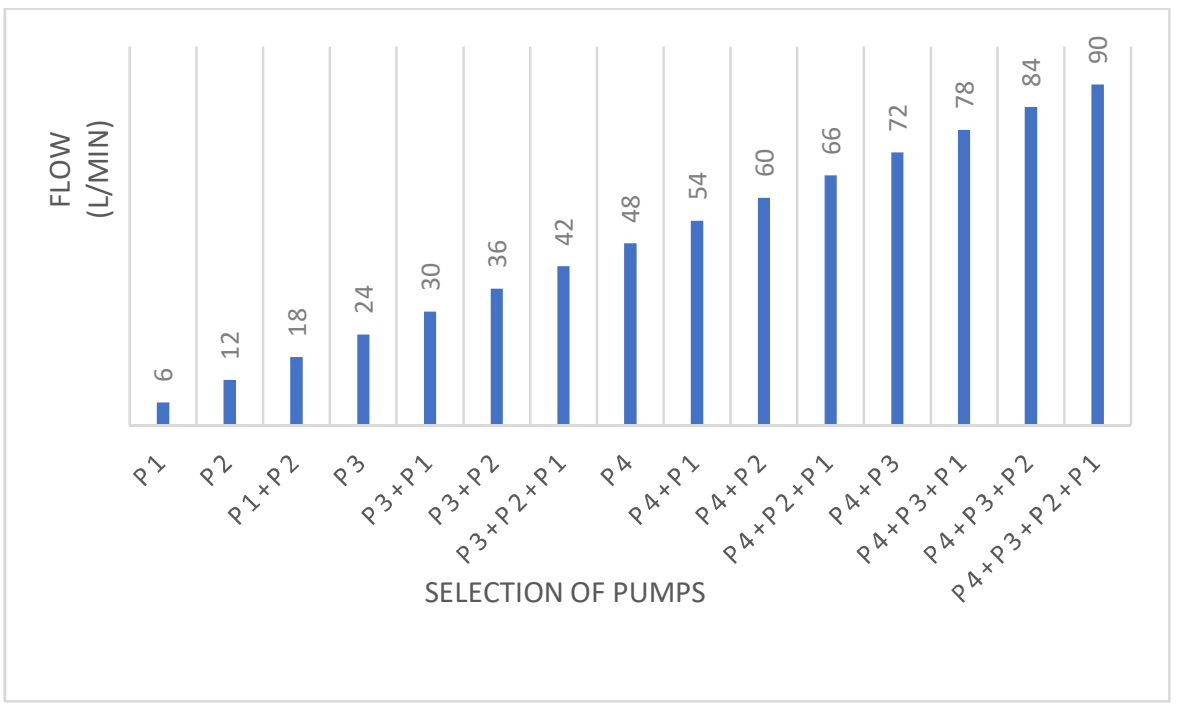

Fig 4. Flow chart

Output power is:

$$
\mathrm{N} \cong \frac{P S \cdot(Q 1+Q 2+Q 3+Q 4)}{600 \eta}, \text { where } Q_{2}=2 Q_{1} ; Q_{3}=2 Q_{2} ; Q_{4}=2 Q_{3}
$$

$\mathrm{N}[\mathrm{kW}]=$ Total output power, $P s[\mathrm{bar}]=$ System pressure, $\mathrm{Q}[1 / \mathrm{min}]=$ system flow composes of the 4 pumps, $\eta=$ total system efficiency

For each of the 15 phases, besides output power $\mathrm{N}$ there is also power installed in excess, that will not be consumed; there will be lost only the part of this power which ensures oil recirculation through the pumps that are not actively involved in that particular phase, plus normal losses caused by operation of the pumping system. The amount of power that is lost is small compared to the amount of useful power consumption. The great advantage of this solution is that besides economical use of power the system allows simple automation, flow accuracy up to $12.5 \%$ and also functional structure quite simple and inexpensive.

\section{Conclusions}

This material refers to the hydraulic systems with 4 fixed displacement pumps, and it highlights certain aspects such as the variable flow pumps equipped with various regulators have high energy efficiency because flow and pressure automatically adapt to customer needs. Reducing energy losses which cause overheating of hydraulic oil leads to simplification of hydraulic system by:

- Although fixed displacement pump hydraulic systems have wasteful behavior in terms of energy, there are a lot of cases in which they can be kept within reasonable limits;

- Complex high-power systems lead to extremely significant energy losses, and therefore hydraulic technology has made considerable progress by using adjustable pumps and more recently with the digital hydraulic witch is an affordable alternative to the complex pump systems. 
- Possibility to mount a smaller capacity tank and to remove the oil cooler, pressure reduction valve or electrical decoupling valves.

This paper has been developed in INOE 2000-IHP and funded by a grant of the Romanian Ministry of Education and Research under the National Research Programme NUCLEU, Financial agreement no. 18N/08.02.2019, Additional Act no. 9/2020, Project acronym: OPTRONICA VI, Research theme PN 19-18.01.02, titled: "Advanced research on developing synergic border architectures used in solving global challenges and improving knowledge-based competitiveness", Phase no. 6, titled: 'Methods, procedures and equipment for experimental validation of mathematical models and numerical simulations, used for modernizing hydraulic equipment in order to reduce energy losses'.

\section{References}

1. G. Matache, St. Alexandrescu, A. G. Pantiru, Gh. Sovaiala, M. Petrache: The analysis of flow losses through dynamic seals of hydraulic cylinders, HIDRAULICA no. 1, pp. 52-60, ISSN 1453 - 7303, (2013)

2. C. Cristescu, L. M. Micu, I. C. Dumitrescu, P. Krevey, "Using Load Sensing control systems to increase energy efficiency of hydrostatic transmissions", HIDRAULICA no. 4, pp. 71-77, ISSN 1453 - 7303, (2015)

3. C. Cristescu, P. Drumea, D. Ion Guta, C. Dumitrescu, "Theoretical research and laboratory experimental tests regarding the dynamic behavior of hydraulic system for energy recovery at the braking of motor vehicle", in: Proc. of The 8-th International Fluid Power Conference-IFK 2012 Fluid Power Drives!, pp. 435 - 446, (www.ifk2012.com), (Dresden, Germany, March 26-28, 2012)

4. PhD.Eng. Heinrich THEISSEN "Fluid Power For Sustainability", International Conference of Hydraulics and Pneumatics-HERVEX, ISSN 1454- 8003, pp. 137-157, (Calimanesti-Caciulata, Romania, November 7-9, 2012)

5. Rudolf SCHEIDL, Helmut KOGLER" Hydraulic Switching Control - State of the Art and Challenges" (2012)

6. Andreas PLÖCKINGER, Bernd WINKLER, Rudolf SCHEIDL," Development and Prototyping of a Compact, Fast 3/2 Way Switching Valve with Integrated Onboard Electronics" The $11^{\text {th }}$ Scandinavian International Conference of Fluid Power, SICFP, ISBN 978-91-7393-589-0, pp. 66-67 (Linkőping, Sweden, 09 June 2-4 2009)

7. Luke WADSLEY," Optimal System Solutions Enabled by Digital Pumps" The $52^{\text {nd }}$ National Conference on Fluid Power, pp.7-13 (Las Vegas, March 23-25, 2011) 